\title{
Home Therapy with Plasma-Derived C1 Inhibitor: A Strategy to Improve Clinical Outcomes and Costs in Hereditary Angioedema
}

\author{
Angelica Petrarolia Veronica Squeglia ${ }^{a} \quad N^{a}$ dia Di Paolab Alessandro Barbarino ${ }^{c}$ \\ Maria Bova $^{a}$ Rosanna Spanò ${ }^{b}$ Gianni Marone ${ }^{a}$ Massimo Triggiani ${ }^{d}$ \\ Departments of ${ }^{a}$ Translational Medical Sciences, ${ }^{b}$ Economics, Management, Institutions, and ${ }^{c}$ Public Health, University \\ of Naples Federico II, Naples, and ${ }^{\mathrm{d}}$ Department of Medicine, University of Salerno, Salerno, Italy
}

\section{Key Words}

Hereditary angioedema . Plasma-derived C1 inhibitor .

Self-administration · Home therapy · Cost minimization

\begin{abstract}
Background: Attacks of hereditary angioedema with $\mathrm{C} 1$ inhibitor deficiency (C1-INH-HAE) are commonly treated in the emergency department. Self-administration is emerging as an effective treatment option. In this study, we assessed the impact of home therapy with plasma-derived $\mathrm{C} 1$ esterase inhibitor (pdC1-INH) concentrate on treatment outcomes and costs. Methods: This is an observational study in C1-INH-HAE patients who switched to home therapy with $\mathrm{pdC1}-\mathrm{INH}$ $\left(\right.$ Berinert ${ }^{\circledR}$ ) after learning intravenous self-infusion in a training course at a center in Southern Italy. Before starting home therapy and after the first year of home therapy, patients were interviewed about their treatment and outcomes during the prior 12 months. Annual costs were analyzed by cost minimization from the Italian health care payer perspective and the societal perspective. Outcomes and costs before and after the switch to home therapy were compared. Results: The training course was attended by 36 participants, 17 (47.2\%) of whom decided to switch to home therapy. This therapy was associated with a significant decrease in the
\end{abstract}

mean annual number of hospitalizations (16.8 vs. $2.1, \mathrm{p}=$ 0.003 ) and missed work/school days ( 20.3 vs. $7.1, p=0.037$ ) compared to conventional treatment. The times from symptom onset to treatment administration and from treatment administration to symptom improvement/resolution were not significantly different between the two strategies. The mean annual per-patient costs decreased with home therapy from EUR 30,010.57 to EUR 26,621.16 (11.3\% saving) and from EUR 29,309.34 to EUR 26,522.04 (9.5\% saving) from the societal and payer perspective, respectively. Conclusions: Home therapy with pdC1-INH is a feasible strategy for the management of C1-INH-HAE and may result in cost savings.

๑) 2015 S. Karger AG, Basel

\section{Introduction}

Hereditary angioedema with C1 inhibitor deficiency (C1-INH-HAE) is a rare autosomal dominant disease [1]. A quantitative or functional deficiency of $\mathrm{C} 1$ esterase inhibitor leads to a dysregulated production of bradykinin, a potent vasodilator and mediator of capillary leakage and thus of angioedema $[1,2]$.

Epidemiologic surveys suggest that C1-INH-HAE affects about 1 in 50,000 individuals worldwide, with no

\section{KARGER 125}

(c) 2015 S. Karger AG, Base

$1018-2438 / 15 / 1664-0259 \$ 39.50 / 0$

E-Mail karger@karger.com

www.karger.com/iaa
Correspondence to: Dr. Maria Bova

Department of Translational Medical Sciences, University of Naples Federico II Via S. Pansini 5

IT-80131 Naples (Italy)

E-Mail bovamaria@ virgilio.it 
ethnic or gender preference [3-5]. In Italy, the minimum prevalence is estimated at 1 in 66,000 according to a recent study [6]. The disease is characterized by recurrent attacks of subcutaneous or submucosal swelling affecting various body sites [2]. Abdominal C1-INH-HAE episodes can be particularly debilitating and associated with severe pain, while laryngeal episodes can be fatal due to the risk of airway obstruction. C1-INH-HAE greatly interferes with the patient's education and career, it has a negative impact on the quality of life, and its economic burden is considerable [7-10].

C1-INH-HAE attacks are a frequent cause of visits to the emergency department (ED) $[11,12]$. Having to attend the ED for treatment inevitably results in delayed treatment. Failure to promptly treat an attack results in a prolonged duration of the episode, increased severity, hospitalization, and a longer hospital stay [13].

Substitution therapy with plasma-derived C1 esterase inhibitor ( $\mathrm{pdCl}$-INH) concentrates, administered by intravenous infusion, has been the first-line treatment for several decades in Europe [14]. A recent important turn in the management of C1-INH-HAE has been the increased use of self-administration for the treatment of attacks [13, 15-17]. In a number of studies, self-administration has been shown to improve patients' quality of life due mostly to early intervention and therapy optimization, reduce the time to the onset of symptomatic relief and complete attack resolution, and decrease the number of visits to the ED [18-22]. International guidelines for home-based therapy for C1-INH-HAE were recently published $[13,17]$. Treatments currently licensed for self-administration include pdC1-INH concentrates (Berinert ${ }^{\circledR}$ and Cinryze ${ }^{\circledR}$ ) and icatibant $\left(\right.$ Firazyr $\left.^{\circledR}\right)[13,16,17]$. pdC1-INH concentrates are administered by intravenous infusion while icatibant, a bradykinin $B_{2}$ receptor antagonist, has the advantage of subcutaneous administration and is supplied in a prefilled syringe. The experience with icatibant is, however, still limited and this treatment is not indicated for children or pregnant or lactating women [17]. pdC1-INH concentrates, on the other hand, have been used for more than 30 years and therefore have a well-defined effectiveness and safety profile [17]. The development and practice of self-administration for the treatment of C1-INH-HAE vary among countries [16, $23,24]$. In Italy, self-therapy for C1-INH-HAE has been in use for a few years but is not consistently practiced across the country.

This article describes the experience of a center located in Southern Italy with introducing patients with C1-INH-
HAE to self-administration, or home therapy, with pdC1INH concentrate. After attending a training course, patients willing to switch to home therapy were followed for 12 months. Clinical outcomes and costs before and after the switch to home therapy were compared. The objective of this study was to define the clinical and economic impact of home therapy with pdC1-INH.

\section{Methods}

\section{Design, Patients, and Self-Administration Training}

This study was conducted between 2010 and 2013 at the Department of Translational Medical Sciences of the University of Naples Federico II, Italy. The primary objective of this study was to investigate the impact of home therapy on treatment effectiveness and costs by comparing these outcomes in the enrolled patients before and after the switch to home therapy.

In 2010, the center started offering to patients affected by $\mathrm{C} 1-$ INH-HAE the option of self-administered treatment with pdC1INH (Berinert ${ }^{\circledR}$; CSL Behring) or icatibant (Firazyr ${ }^{\circledR}$; Shire). Icatibant is administered subcutaneously and patients are taught self-administration during regular visits [25], while pdC1-INH is administered by intravenous infusion [26]. A training program to instruct patients on self-administration of pdC1-INH by intravenous infusion, consisting of a 1-day course, was started. The Italian Association of HAE Patients had an important role in promoting the development of the training program. As of June 2014, a total of 3 courses had been given at the center. This analysis included the participants of the first two training courses.

The training course was designed by physicians of the center and by a nurse with experience teaching self-administration to patients with hemophilia, and it consisted of a theory session (approximately $2 \mathrm{~h}$ ) and a practical session (approximately $3 \mathrm{~h}$ ). The input from members of the Italian Association of HAE Patients was also relevant. The theory session was held by a physician and a nurse and covered the following topics: general information on C1-INH-HAE and current treatment options; general information on pdC1-INH and intravenous administration; techniques for intravenous infusion, use of needles and syringes, and how to inject under sterile conditions; storage and reconstitution of lyophilized pdC1-INH according to the manufacturer's instructions [26]; what to do in case of a laryngeal attack or if unable to perform intravenous infusion, and management of adverse reactions. During the practical session held by a nurse, participants were taught how to administer an intravenous infusion and could practice intravenous injection on a simulator arm. Participants were also further advised on the importance of keeping a diary, which involved recording the number of administrations, the drug lot, the time to symptom improvement and to complete resolution, and the site and severity of the episode. The first self-administration was performed at the center or at home under the supervision of a nurse or a physician.

As recommended by current guidelines, the training program was offered to all C1-INH-HAE patients referred to the center and to their families/caregivers $[13,17]$. This study was approved by the local Institutional Review Board and was conducted in accor- 
dance with the Declaration of Helsinki. Patients whose data were collected for the present analysis signed an informed consent form.

\section{Assessment of Home Therapy Outcomes}

In this article the term 'home therapy' refers to the injection of pdC1-INH practiced at home by a person - patient, family member, or caregiver - trained at the course held within the present study, as opposed to 'conventional therapy' administered by a health care professional.

Patients attending the training course could switch to home therapy only after they/their family members or caregivers had acquired adequate skills of intravenous infusion (as judged by the training nurse) and only if they/their family members or caregivers felt comfortable with this approach. Patients were advised to refer to the nearest ED in case of a laryngeal attack.

Patients switching to home therapy were interviewed before starting home therapy and 12 months after the switch to it by means of a questionnaire addressing the following issues concerning outcomes and treatment during the prior 12 months: overall disease burden (number of attacks and site of the attack, number of visits to the ED, number of hospital admissions and length of stay, need for emergency diagnostic and surgical procedures, and number of missed work or school days); additional disease treatments or assessments (laboratory exams, radiography, ECG, echocardiogram, gastrointestinal endoscopy, medications, and infusion at home administered by a healthcare professional); quality of therapy administration (time to infusion, pdC1-INH dose, selfadministration or administration by a family member, administration by a health care professional), and treatment outcomes (time to symptom improvement and to symptom resolution and treatment-related adverse events). The patients provided the answers to the questionnaire based on their diaries and recollection. The reliability of the data recorded in the diaries was checked repeatedly at control visits for drug prescriptions. The correctness of data related to the 12-month period before the switch to home therapy was confirmed by comparing the data from diaries to those recorded at the ED. Patient demographic characteristics (age, gender, occupation, distance from home to the nearest ED, and occupation of family members) were also recorded.

\section{Estimate of Costs}

The economic impact of the switch to home therapy was studied by means of a cost minimization analysis. The estimated perpatient annual costs for home therapy with pdC1-INH were compared to those for pdC1-INH therapy administered by a health care professional. Per-patient annual costs were estimated based on the information recorded in the questionnaire used to interview patients and described above. The analysis was conducted from the perspective of the Italian National Healthcare System (payer), including only medical costs (i.e. medical resources used), and from the societal perspective, including medical costs, costs of missed work/school days, and travel expenses.

The costs of visits to the ED, of procedures/assessments performed, and of hospitalization were calculated based on the fees of the Regione Campania for 2013 and the diagnosis-related groups system of the Italian National Healthcare System [27, 28]. Drug acquisition costs were estimated based on the prices agreed upon by the drug manufacturer and the local agency managing drug tenders [29]. Travel expenses to the hospital/ED by car were estimat- ed based on the costs indicated by Automobile Club Italia for 2014 [30]. The cost of a missed workday was derived from average Italian salaries for 2010 [31]. For household work, the cost of a missed workday was estimated by means of the substitution approach [32]. The cost of a missed school day was estimated based on the average daily public expenditure for education in 2012 indicated by the Organisation for Economic Cooperation and Development [33].

\section{Data Analysis and Statistics}

The mean $( \pm S D)$ annual, per-patient number of hospitalizations (including visits to the ED) and missed work or school days, the mean time from attack onset to therapy administration, and treatment outcomes (i.e. the mean time to symptom improvement and to symptom resolution) with conventional administration were calculated and compared to those after the switch to home therapy. The statistical significance of the difference between values was tested by means of the $\chi^{2}$ test ( $p \leq 0.05$ was considered statistically significant). The economic analysis was based on the comparison of total annual costs (entire study population) and mean per-patient annual costs before and after switching to home therapy, according to the perspective considered.

\section{Results}

\section{Self-Administration Training Attendance}

Self-administration training was proposed to all $\mathrm{C} 1$ INH-HAE patients referred to the study center at the beginning of this study $(n=60)$. Of these, 24 were interested in switching to home therapy and attended the course. These patients had so far been treated with intravenous infusions of pdC1-INH concentrate either at the nearest ED or at home by a nurse or a physician. Of the patients who declined to participate, some were treating their acute attacks with subcutaneous icatibant and were therefore already practicing self-administration, while others had a very low attack rate because they were on long-term prophylaxis with danazol. A few patients were unwilling to switch to self-administration for personal reasons including fear of self-injection and a lack of self-confidence.

The first two self-administration training courses organized at the center were attended by 36 participants $(24$ patients and 12 family members). At the end of the training, 17 participants $(47.2 \%, 4$ patients and 13 family members) felt confident about the possibility of practicing home therapy. The remaining 19 participants were still feeling uncomfortable about self-injection but did not exclude a switch to this option in the foreseeable future.

Among the 17 participants starting home therapy, 10 learned quickly how to self-inject or inject the pdC1-INH concentrate and were autonomous after completing the 
course. The other 7 participants required additional assistance at home (on average 6 additional sessions with a nurse per participant) before feeling fully comfortable with self-injection or injection.

The demographic characteristics of the 17 patients who switched to home therapy (53\% female, mean age 32.2 years) are shown in table 1 . Four of these patients were self-injecting the pdC1-INH concentrate, while 13 patients were injected by a trained family member.

\section{Outcomes of Home Therapy}

Compared with the conventional management of acute HAE attacks, home therapy with pdC1-INH concentrate was associated with a significantly lower number of hospitalizations (mean annual per-patient number of hospitalizations, respectively: 16.8 vs. $2.1, \mathrm{p}=0.003$ ) (table 2). Home therapy was also associated with a significantly lower number of missed work and school days (mean annual per-patient number of missed work/school days, respectively: 20.3 vs. $7.1, p=0.037$ ) (table 2 ). In addition, the mean time from symptom onset to pdC1-INH infusion was shortened from 3.2 to $1.9 \mathrm{~h}$ (difference not statistically significant). Symptom improvement and resolution were achieved earlier compared to the results of conventional administration; however, the difference between the two treatment strategies was not statistically significant ( 84 vs. $54 \mathrm{~min}$ for symptom improvement and 12.8 vs. $10.8 \mathrm{~h}$ for symptom resolution, respectively) (table 2). The numbers of $\mathrm{C} 1$-INH concentrate administrations over the 12 months before switching to home therapy (440 administrations) and after the switch to home therapy (399 administrations) were not significantly different. Home therapy proved safe. Over the 12-month observation period, no unexpected or severe adverse events were reported with home therapy.

\section{Economic Impact of Home Therapy}

The results of the cost minimization analysis are shown in table 3. After the switch to home therapy, the costs for the entire study population decreased from EUR $510,179.69$ to EUR $452,559.80$ according to the societal perspective, and from EUR 498,258.73 to EUR 450,874.66 according to the perspective of the Italian National Healthcare System. The mean per-patient annual costs decreased from EUR 30,010.57 with conventional treatment to EUR 26,621.16 with home therapy from the societal perspective (11.3\% saving), and from EUR 29,309.34 to EUR $26,522.04$ from the payer perspective (9.5\% saving) (table 3). With the exception of medication use, which remained unchanged after the switch to home therapy, the
Table 1. Summary of the demographic characteristics of patients who switched to home therapy (either self-administered or administered by a trained family member)

\begin{tabular}{rlll}
\hline Patient No. & Gender & Age, years & Occupation \\
\hline 1 & M & 11 & Student \\
2 & F & 35 & Housewife \\
3 & F & 34 & Unemployed \\
4 & F & 31 & Housewife \\
5 & M & 32 & Self-employed \\
6 & F & 40 & Housewife \\
7 & F & 44 & Housewife \\
8 & F & 16 & Student \\
9 & M & 42 & Driver \\
10 & M & 11 & Student \\
11 & F & 75 & Retired \\
12 & M & 44 & Unemployed \\
13 & M & 38 & Hairdresser \\
14 & F & 13 & Student \\
15 & F & 45 & Housewife \\
16 & M & 24 & Bartender \\
17 & M & 13 & Student \\
\hline
\end{tabular}

$\mathrm{M}=$ Male; $\mathrm{F}=$ female.

Table 2. Disease burden and treatment outcomes before and after switching to home therapy

\begin{tabular}{lcc}
\hline & $\begin{array}{l}\text { Before home } \\
\text { therapy }\end{array}$ & $\begin{array}{l}\text { After home } \\
\text { therapy }\end{array}$ \\
\hline Hospitalizations ${ }^{\mathrm{a}}$, $\mathrm{n}$ & $16.8 \pm 19.2$ & $2.1 \pm 3.9^{\mathrm{b}}$ \\
Time to therapy administration, $\mathrm{h}$ & $3.2 \pm 5.8$ & $1.9 \pm 5.7$ \\
Time to symptom improvement, $\min$ & $84 \pm 1.1$ & $54 \pm 0.5$ \\
Time to symptom resolution, $\mathrm{h}$ & $12.8 \pm 12.9$ & $10.8 \pm 12.9$ \\
Missed work/school days, $\mathrm{n}$ & $20.3 \pm 23.9$ & $7.1 \pm 15.5^{\mathrm{c}}$ \\
\hline
\end{tabular}

All data are means \pm SD. ${ }^{\text {a }}$ Including visits to the ED and hospital admissions. ${ }^{\mathrm{b}} \mathrm{p}$ value $\left(\chi^{2}\right.$ test $)=0.003 .{ }^{\mathrm{c}} \mathrm{p}$ value $\left(\chi^{2}\right.$ test $)=$ 0.037 .

use of the other resources considered in the analysis decreased significantly, leading to substantial (80-100\%) decreases in costs for ED visits, hospital admissions, missed work/school days, and travel expenses (table 3 ).

\section{Discussion}

The practice of self-administered C1-INH replacement therapy for on-demand treatment or for prophylaxis of C1-INH-HAE, though not equally developed worldwide, is increasingly considered a valuable ap- 
Table 3. Summary of costs related to the management of C1-INH-HAE before and after the switch to home therapy with pdC1-INH

\begin{tabular}{|c|c|c|c|c|c|c|c|}
\hline \multirow[t]{2}{*}{ Resource } & \multicolumn{2}{|c|}{ Before home therapy } & \multicolumn{2}{|c|}{ After home therapy } & \multicolumn{2}{|l|}{$\Delta$} & \multirow{2}{*}{$\begin{array}{l}\text { Savings, } \\
\%\end{array}$} \\
\hline & $\begin{array}{l}\text { study population } \\
(\mathrm{n}=17)\end{array}$ & $\begin{array}{l}\text { per } \\
\text { patient }\end{array}$ & $\begin{array}{l}\text { study population } \\
(\mathrm{n}=17)\end{array}$ & $\begin{array}{l}\text { per } \\
\text { patient }\end{array}$ & $\begin{array}{l}\text { study population } \\
(\mathrm{n}=17)\end{array}$ & $\begin{array}{l}\text { per } \\
\text { patient }\end{array}$ & \\
\hline \multicolumn{8}{|l|}{ Medical resources } \\
\hline pdC1-INH concentrate & $481,805.00$ & $28,341.47$ & $449,499.00$ & $26,441.12$ & $32,306.00$ & $1,900.35$ & 6.7 \\
\hline ED visits & $8,201.73$ & 482.45 & $1,375.66$ & 80.92 & $6,826.07$ & 401.53 & 83.2 \\
\hline Hospital admissions & $8,252.00$ & 485.41 & 0 & 0 & $8,252.00$ & 485.41 & 100.0 \\
\hline Total & $498,258.73$ & $29,309.34$ & $450,874.66$ & $26,522.04$ & $47,384.07$ & $2,787.30$ & 9.5 \\
\hline Missed work/school days & $11,026.25$ & 648.60 & $1,514.04$ & 89.06 & $9,512.21$ & 559.54 & 86.3 \\
\hline Travel expenses & 894.72 & 52.63 & 171.10 & 10.06 & 723.62 & 42.57 & 80.9 \\
\hline Total & $510,179.69$ & $30,010.57$ & $452,559.80$ & $26,621.16$ & $57,619.89$ & $3,389.41$ & 11.3 \\
\hline
\end{tabular}

Costs are in EUR and were estimated for Italy from the payer (Italian National Healthcare System) and societal perspectives.

proach for optimizing both patient management and the use of resources. The present study describes how this approach was established in a center in Southern Italy and provides a first estimate of the impact of the switch to home therapy on patient outcomes and costs. Almost $50 \%$ of the 36 participants (including patients and family members or caregivers) of the self-administration training program offered at the center learned to self-inject or to inject $\mathrm{C} 1-\mathrm{INH}$ concentrate intravenously. The switch to home therapy was associated with a statistically significant decrease in the number of visits to the ED and hospital admissions and in the number of missed work or school days. A tendency towards shorter times to therapy administration and to symptom relief was also reported with home therapy.

This study confirms that self-administration of C1INH concentrate infusion can be learned by patients and their families. Overall, patients and family members reacted positively to the proposal of using self-administration, with a proportion of patients switching to home therapy similar to that observed in other studies [34-36]. For example, a recently published Danish study that followed $80 \mathrm{C} 1$-INH-HAE patients for 11 years found that by the end of 2012, forty-nine percent of the patients were practicing self-therapy for acute attacks [34]. However, several barriers to self-administration still exist $[23,37]$. As pointed out by a recent survey, the most common obstacles to self-administration include: difficulty practicing intravenous injection, a shortage of nursing resources, the patient's mental capacity, and loss of skills as a result of a low attack frequency [15]. In addition, reluctance to prescribe self-administration has been reported also among physicians $[15,23]$.

pdC1-INH Home Therapy in C1-INH-HAE
In our study, home therapy with pdC1-INH concentrate resulted in significantly fewer hospitalizations and work or school days lost, in agreement with other published reports $[34,36]$. The Danish survey mentioned above found a decrease of $84 \%$ in the number of acute hospital visits (from 3.8 visits/year before learning selfadministration to 0.6 visits/year after switching to selftherapy) [34]. Compared to the findings from other studies, the improvement in time to symptom resolution in our patients was less substantial (from 12.8 to $10.8 \mathrm{~h}$ ) and failed to reach statistical significance, as did the difference in time to therapy administration (from 3.2 to $1.9 \mathrm{~h}$ ). For example, a study involving 43 patients on selfadministration followed up for 3.5 years found statistically significant decreases in the time from attack onset to C1-INH administration ( 3.4 vs. $1.4 \mathrm{~h}, \mathrm{p}=0.01$ ) and in the time from therapy administration to angioedema resolution (13.8 vs. $5.9 \mathrm{~h}, \mathrm{p}=0.01)$ after the switch from conventional administration to self-administration [20]. Published evidence suggests that the early administration of C1-INH concentrate is associated with a more rapid relief of symptoms compared to delayed treatment [19-21, 38, 39]. Recently, a study conducted within the Icatibant Outcome Survey (IOS) clearly demonstrated that the attack duration was significantly shorter in patients treated within $1 \mathrm{~h}$ of symptom onset compared to patients treated after $1 \mathrm{~h}(6.1$ vs. $16.8 \mathrm{~h}, \mathrm{p}<0.001)$ [40]. In addition, treatment within $1 \mathrm{~h}$ of symptom onset significantly reduced the time to attack resolution (5.8 vs. $8.8 \mathrm{~h}, \mathrm{p}<0.05$ ) [40]. Based on these findings, the less rapid relief of symptoms observed in our patients compared to the data reported in the literature may be explained by a longer time to treatment administration in

Int Arch Allergy Immunol 2015;166:259-266 263 
our study. Why the time to treatment administration remained relatively long in our patients is currently unclear. It is possible that the 12-month observation period of the present study was not sufficient to detect clear improvements in the time to treatment administration because patients and family members, though able to inject intravenously, were still relatively inexperienced with home therapy and unable to react promptly to an attack. It is also possible that some of our patients might have benefitted from additional training and assistance at home. Notably, 2 recent studies investigating the feasibility of C1-INH concentrate self-administration found that on average patients needed 5 training sessions at home to be trained, and that the preferred form of teaching was at home by a visiting nurse in the presence of a family member or caregiver [35, 37]. As recommended by current guidelines, refresher training at regular intervals may also help to further improve and maintain the acquired skills [17].

Self-administered therapy is viable and effective also in children and adolescents [41]. The population of the present analysis included 5 children/adolescents who were injected by members of their families trained at the course, with safety and efficacy outcomes comparable to those of the entire population. A substantial benefit from the switch to self-administration/home therapy emerged from a recent study in 20 pediatric patients (median age 14 years) with C1-INH-HAE showing that home therapy self-administered or administered by a parent was associated with a significantly shorter time from symptom onset to treatment ( $15 \mathrm{vs.} 67.5 \mathrm{~min}$ during physician-administered therapy) [19]. The switch to home therapy resulted also in a reduction of the mean annual number of days in hospital from 3.8 during physician-administered therapy to 0.11 .

In the present study, the switch to home therapy was associated with a decrease in the number of treatment administrations with, however, no statistically significant difference between conventional administration and home therapy. It is currently unclear how the switch from conventional treatment to self-administration impacts the number of C1-INH-HAE attacks being treated. In contrast with our findings suggesting a decreasing trend, the Danish survey mentioned above showed that patients on self-therapy had a 3-fold increase in the number of treated attacks [34]. The authors pointed out that some patients on self-administration may overuse the therapy by treating false prodromes or minor attacks [34]. This risk exists, and patients on self-administration should be encouraged to keep a diary documenting their attacks and the treatment administered to facilitate monitoring of the disease and treatment course.

To our knowledge, this is the first attempt to assess the impact of the switch to home therapy with pdC1INH concentrate on expenditures. According to our estimate, home therapy was associated with a mean annual decrease in medical costs reaching EUR 2,800 per patient (almost 10\% saving) from the perspective of the Italian National Healthcare System. Drugs acquisitions costs, which have a considerable impact on total medical expenses, may not change significantly from conventional treatment to self-administration, as pointed out above. A recent study that analyzed the costs of HAE management in the US highlighted the urgent need for strategies aimed at containing costs, as assistance programs funded by HAE drugs manufacturers to prevent elevated out-of-pocket expenses for patients may not be sustainable in the future [10]. As for the economic implications of the switch to self-administration with other HAE medications, a study conducted from the perspective of the Spanish National Health System found that the estimated health care costs per acute attack decreased from EUR 1,272.42 for health care professionaladministered icatibant to EUR 1,182.62 for self-administered icatibant, with an average savings per attack of EUR $89.80(7.06 \%)$ arising mostly from a reduction in the number of visits to the ED and other medical facilities [42]. The social costs (direct plus indirect costs) per acute attack decreased from EUR 1,315.14 to EUR $1,193.84$, with an average savings of EUR 121.30 per attack (9.22\%) [42]. In the present analysis we did not include the costs of the self-administration training program, a nonrecurring expenditure. The costs related to the course were limited, as the training program was held at the center by the health care personnel of the center, within their working hours, and did not involve any extra working hours. The cost of the materials for the course was also negligible.

In line with the findings of other studies in patients practicing C1-INH self-administration, our patients did not experience any treatment-related adverse events during home therapy, and the new procedure was well tolerated [18-22].

The present study has several limitations, including a small sample size and a relatively short duration of follow-up after switching to home therapy. With regard to the limited number of patients, it should be noted that $\mathrm{C} 1-\mathrm{INH}-\mathrm{HAE}$ is a rare disease and that the enrollment of large populations is very difficult. As for the duration of follow-up, the first 12 months of self-ad- 
ministration may not be optimal for describing a fully autonomous and extensively experienced patient using routinely self-therapy and able to promptly use the drug at symptom onset. In addition, after the training program, most patients continued to receive some assistance at home by medical staff. This may have resulted, for example, in improved compliance to treatment recommendations and diary updating. Another limitation of our study is the use of patient-reported outcomes, which may involve anamnestic bias. To limit this problem, great care was taken to motivate the patients to fill out their diary on a regular basis so as to avoid reporting errors.

\section{Conclusions}

This study showed that self-administration of the pdC1-INH concentrate was easy to learn and feasible. The management of acute C1-INH-HAE attacks based on home therapy significantly reduced the number of visits to the hospital and the number of lost work or school days. The switch to home therapy also led to a decrease in total costs, arising from the significant reduction of the number of hospitalization and missed work and school days. These findings clearly need to be confirmed by adequately designed studies and in the long term. Assessing the impact of home therapy on the health-related quality of life will also be important. Based on these preliminary observations, home therapy with pdC1-INH concentrate appears to be a viable and effective strategy with a favorable impact on costs.

\section{Acknowledgements}

We thank Lorenza Lanini and Ray Hill, independent medical writers, who provided editorial assistance and journal styling services prior to submission on behalf of Springer Healthcare Communications. Editorial services were funded by CSL Behring, Italy.

\section{Disclosure Statement}

Maria Bova and Angelica Petraroli have received sponsorship for educational purposes, have been paid for providing consultancy services, and have taken part in clinical trials sponsored by Shire, Pharming NV, CSL-Behring, and SOBI. Veronica Squeglia has received sponsorship for educational purposes and has taken part in clinical trials sponsored by Shire and CSL Behring. Gianni Marone has taken part in clinical trials sponsored by Shire and Pharming NV. Massimo Triggiani has consultancy agreements and has been an invited speaker for Shire Human Genetic Therapies, Inc., ViroPharma, SOBI, and CSL Behring. Nadia Di Paola, Rosanna Spanò, and Alessandro Barbarino have no conflicts of interest to declare.

\section{References}

1 Cicardi M, Aberer W, Banerji A, Bas M, Bernstein JA, Bork K, Caballero T, Farkas H, Grumach A, Kaplan AP, Riedl MA, Triggiani M, Zanichelli A, Zuraw B: Classification, diagnosis, and approach to treatment for angioedema: consensus report from the Hereditary Angioedema International Working Group. Allergy 2014;69:602-616.

2 Longhurst H, Cicardi M: Hereditary angiooedema. Lancet 2012;379:474-481.

3 Bygum A: Hereditary angio-oedema in Denmark: a nationwide survey. Br J Dermatol 2009;161:1153-1158.

4 Ghazi A, Grant JA: Hereditary angioedema: epidemiology, management, and role of icatibant. Biologics 2013;7:103-113.

5 Roche O, Blanch A, Caballero T, Sastre N, Callejo D, Lopez-Trascasa M: Hereditary angioedema due to $\mathrm{C} 1$ inhibitor deficiency: patient registry and approach to the prevalence in Spain. Ann Allergy Asthma Immunol 2005; 94:498-503.

6 Zanichelli A, Arcoleo F, Barca MP, Borrelli P, Bova M, Cancian M, Cicardi M, Cillari E, De Carolis C, De Pasquale T, Del Corso I, Cesina- ro Di Rocco P, Guarino MD, Massaro I, Minale P, Montinaro V, Neri S, Perricone S, Pucci S, Quattrocchi P, Rossi O, Triggiani M, Zanierato $G$, Zoli A: A nationwide survey of hereditary angioedema due to $\mathrm{C} 1$ inhibitor deficiency in Italy. Orphanet $J$ Rare Dis 2015;10:11.

7 Aygören-Pürsün E, Bygum A, Beusterien K, Hautamaki E, Sisic Z, Wait S, Boysen HB, Caballero T: Socioeconomic burden of hereditary angioedema: results from the hereditary angioedema burden of illness study in Europe. Orphanet J Rare Dis 2014;9:99.

8 Nordenfelt $\mathrm{P}$, Dawson S, Wahlgren CF, Lindfors A, Malbris L, Björkander J: Quantifying the burden of disease health state in patients with hereditary angioedema in Sweden. Allergy Asthma Proc 2014;35:185-90.

9 Wilson DA, Bork K, Shea EP, Rentz AM, Blaustein MB, Pullman WE: Economic costs associated with acute attacks and long-term management of hereditary angioedema. Ann Allergy Asthma Immunol 2010;104:314-320.

10 Tilles SA, Borish L, Cohen JP: Management of hereditary angioedema in 2012: scientific and pharmacoeconomic perspectives. Ann Allergy Asthma Immunol 2013;110:70-74.

11 Cicardi M, Bellis P, Bertazzoni G, Cancian M, Chiesa M, Cremonesi P, Marino P, Montano $\mathrm{N}$, Morselli C, Ottaviani F, Perricone R, Triggiani $\mathrm{M}$, Zanichelli A: Guidance for diagnosis and treatment of acute angioedema in the emergency department: consensus statement by a panel of Italian experts. Intern Emerg Med 2014;9:85-92.

12 Zilberberg MD, Nathanson BH, Jacobsen T, Tillotson G: Descriptive epidemiology of hereditary angioedema hospitalizations in the United States, 2004-2007. Allergy Asthma Proc 2011;32:248-254.

13 Cicardi M, Craig TJ, Martinez-Saguer I, Hebert J, Longhurst HJ: Review of recent guidelines and consensus statements on hereditary angioedema therapy with focus on self-administration. Int Arch Allergy Immunol 2013;161(suppl 1):3-9.

14 Bork K, Steffensen I, Machnig T: Treatment with C1-esterase inhibitor concentrate in type I or II hereditary angioedema: a systematic literature review. Allergy Asthma Proc 2013;34:312-327. 
15 Boysen HB, Bouillet L, Aygoren-Pursun E: Challenges of $\mathrm{C} 1$-inhibitor concentrate selfadministration. Int Arch Allergy Immunol 2013;161(suppl 1):21-25.

16 Caballero T, Sala-Cunill A, Cancian M, Craig TJ, Neri S, Keith PK, Boccon-Gibod I, Bethune C, Bork K: Current status of implementation of self-administration training in various regions of Europe, Canada and the USA in the management of hereditary angioedema. Int Arch Allergy Immunol 2013; 161(suppl 1):10-16.

17 Longhurst HJ, Farkas H, Craig T, AygorenPursun E, Bethune C, Bjorkander J, Bork K, Bouillet L, Boysen H, Bygum A, Caballero T, Cicardi M, Dempster J, Gompels M, Gooi J, Grigoriadou S, Huffer U, Kreuz W, Levi MM, Long J, Martinez-Saguer I, Raguet M, Reshef A, Bowen T, Zuraw B: HAE international home therapy consensus document. Allergy Asthma Clin Immunol 2010;6:22.

18 Bygum A, Andersen KE, Mikkelsen CS: Selfadministration of intravenous C1-inhibitor therapy for hereditary angioedema and associated quality of life benefits. Eur J Dermatol 2009; 19:147-151.

19 Kreuz W, Rusicke E, Martinez-Saguer I, Aygoren-Pursun E, Heller C, Klingebiel T: Home therapy with intravenous human C1-inhibitor in children and adolescents with hereditary angioedema. Transfusion 2012;52:100-107.

20 Levi M, Choi G, Picavet C, Hack CE: Self-administration of C1-inhibitor concentrate in patients with hereditary or acquired angioedema caused by C1-inhibitor deficiency. J Allergy Clin Immunol 2006;117:904-908.

21 Bork K, Meng G, Staubach P, Hardt J: Treatment with $\mathrm{C} 1$ inhibitor concentrate in abdominal pain attacks of patients with hereditary angioedema. Transfusion 2005;45:17741784.

22 Rizk C, Karsh J, Santucci S, Yang W: Self-administration of intravenous $\mathrm{C} 1$ esterase in- hibitor in hereditary angioedema. CMAJ 2013; 185:791-792.

23 Craig TJ. Recent advances in hereditary angioedema self-administration treatment: summary of an international hereditary angioedema expert meeting. Int Arch Allergy Immunol 2013;161(suppl 1):26-27.

24 Symons C, Rossi O, Magerl M, Andritschke K: Practical approach to self-administration of intravenous C1-INH concentrate: a nursing perspective. Int Arch Allergy Immunol 2013; 161(suppl 1):17-20.

25 SPC icatibant. 2013. http://www.ema.Europa. $\mathrm{Eu} /$ docs/en_gb/document_library/epar_-_ product_information/human/000899/ wc500022966.Pdf (accessed June 12, 2014).

26 SPC Berinert. 2013. https://www.Medicines. Org.Uk/emc/medicine/2 $1650 / \mathrm{spc} /$ berinert+500+iu/ (accessed June 12, 2014).

27 Decreto ministeriale del 18/10/2012. http:// www.Crob.It/crob/files/docs/10/63/33/ document_file_106333.Pdf (accessed June 12, 2014).

28 Decreto del commissario ad acta No 32 del 27/03/13. http://www.Arsan.Campania.It/ documents/10157/2fa38e $7 \mathrm{f}-28 \mathrm{c} 4-470 \mathrm{e}$ b7c0-3fef24b080ac (accessed June 12, 2014).

29 Determinazione No 57 del 17 giugno 2013. http://www.Soresa.It (accessed June 12, 2014).

30 ACI. 2014. http://servizi.Aci.It/ckinternet/ selezionemodello (accessed June 12, 2014).

31 ISTAT: Struttura delle retribuzioni 2010. 2013. http://www.Istat.It/it/archivio/83362 (accessed June 12, 2014).

32 Allen DW: An alternative method for assessing the value of housewife services. 2004. http://www.economica.ca/ew09_1p2.htm (accessed June 12, 2014).

33 OECD: Education at a glance 2012: OECD indicators. 2012.http://www.oecd.org/edu/ EAG\%202012_e-book_EN_200912.pdf (last accessed June 12, 2014).
34 Bygum A: Hereditary angioedema - consequences of a new treatment paradigm in Denmark. Acta Derm Venereol 2014;94:436441.

35 Gregory C, Landmesser LM, Corrigan L, Mariano D: Feasibility of home infusion and self-administration of nanofiltered $\mathrm{C} 1$ esterase inhibitor for routine prophylaxis in patients with hereditary angioedema and characterization of a training and support program. J Infus Nurs 2014;37:29-34.

36 Rusicke E, Martinez-Saguer I, AygörenPürsün E, Kreuz F: Home treatment in patients with hereditary angioedema (HAE) (abstract). J Allergy Clin Immunol 2006; 117:S180.

37 Tuong LA, Olivieri K, Craig TJ. Barriers to selfadministered therapy for hereditary angioedema. Allergy Asthma Proc 2014;35:250-254.

38 Tourangeau LM, Castaldo AJ, Davis DK, Koziol J, Christiansen SC, Zuraw BL: Safety and efficacy of physician-supervised selfmanaged $\mathrm{C} 1$ inhibitor replacement therapy. Int Arch Allergy Immunol 2012;157:417-424.

39 Bork K, Staubach P, Hardt J. Treatment of skin swellings with $\mathrm{C} 1$-inhibitor concentrate in patients with hereditary angioedema. $\mathrm{Al}$ lergy 2008;63:751-757.

40 Maurer M, Aberer W, Bouillet M, Caballero T, Fabien V, Kanny G, Kaplan A, Longhurst $\mathrm{H}$, Zanichelli A; IOS Investigators: Hereditary angioedema attacks resolve faster and are shorter after early icatibant treatment. PLoS One 2013;8:e53773.

41 Abdel-Karim O, Dizdarevic A, Bygum A: Hereditary angioedema: children should be considered for training in self-administration. Pediatr Dermatol 2014;31:e132-135.

42 Blasco AJ, Lazaro P, Caballero T, Guilarte M: Social costs of icatibant self-administration vs. health professional-administration in the treatment of hereditary angioedema in Spain. Health Econ Rev 2013;3:2. 